\title{
Rancang Bangun Alat Pendeteksi Ketinggian Air dan Alarm Pemberitahuan Antisipasi Datangnya Banjir Berbasis Arduino Uno
}

\author{
Ibnu Agung Deswiyan ${ }^{* 1}$, Solikhun ${ }^{2}$, Sumarno $^{3}$, Poningsih $^{4}$, Sundari Retno Andani ${ }^{5}$ \\ 1,2,3,4,5 Teknik Informatika, STIKOM Tunas Bangsa Pematangsiantar, Indonesia
}

Email: 1ibnu97@gmail.com, ${ }^{2}$ Solikhun@amiktunasbangsa.ac.id, ${ }^{3}$ sumarno@amiktunasbangsa.ac.id, ${ }^{4}$ poningsih@amiktunasbangsa.ac.id, ${ }^{5}$ sundariretno@amiktunasbangsa.ac.id

\begin{abstract}
Abstrak
Kebanjiran adalah musibah yang tidak dapat diramalkan dan tidak terduga. Kebanjiran bisa menjadi masalah yang kerap saat ini sering terjadi khususnya di negara berkembang salah satunya Indonesia. Sistem Arduino Water Level merupakan salah satu alat microcontroller yang bertugas untuk memberitahu batas tinggi air pada suatu tempat. Penelitian ini bertujuan untuk mengetahui ketinggian air dan menjadi alarm pemberitahuan antisipasi akan datangnya kebanjiran sehingga dapat mengurangi jumlah korban jiwa dalam suatu daerah atau disuatu tempat yang bisa dikategorikan rawan terkena musibah kebanjiran. Dengan Mengunakan arduino dan water level ini dapat mendeteksi batas ketinggian air dan menjadi alarm pemberitahuan sebelum musibah kebanjiran datang. Hasil dari penelitian ini didapatkan pada tinggi akuarium kaca dengan ukuran $30 \mathrm{~cm}$ dan lebar akuarium $15 \mathrm{~cm}$. Terdapat nilai pada batas tinggi air dengan status darurat siaga 1 yaitu pada validasi data dengan tinggi air $1 \mathrm{~cm}$ sampai dengan $10 \mathrm{~cm}$ dihitung secara mundur atau dari bawah.
\end{abstract}

Kata kunci: Arduino, Mikrokontroller, Water Level

\section{Abstract}

Flooding is an unforeseeable and unpredictable disaster. Flooding can be a problem that often happens nowadays, especially in developing countries, one of which is Indonesia. Arduino Water Level System is one of the microcontroller devices whose job is to tell the water level limit at a place. This study aims to determine the water level and alarm to anticipate the coming flood so that it can reduce the number of casualties in an area or somewhere that can be categorized prone to flooding. By using arduino and water level system, it can detect water level limits and be a notification alarm before floods come. The results of this study were obtained at a glass aquarium with a size of $30 \mathrm{~cm}$ and a width of $15 \mathrm{~cm}$. There is a value on the water level limit with an emergency alert status of 1 , namely the data validation with a water level of $1 \mathrm{~cm}$ to $10 \mathrm{~cm}$, calculated backwards or from below.

Keywords: Arduino, Microkontroller, Water Level

\section{PENDAHULUAN}

Seiring waktu berjalan bumi semakin menua dan banyak masalah yang sering terjadi seperti bencana alam yang tidak pernah diinginkan manusia. Faktor dimana bencana alam memiliki definisi yaitu serangkaian peristiwa yang disebabkan oleh gejala-gejala alam sehingga peristiwa tersebut menyebabkan kerugian materi, kerusakan lingkungan dan korban jiwa. Pada umumnya bencana alam yang paling sering terjadi adalah kebanjiran. Banjir merupakan peristiwa terendamnya suatu wilayah secara tiba-tiba dikarenakan tingginya jumlah level debit air yang besar akibat aliran sungai yang tersumbat. Peristiwa banjir terjadi karena curah hujan yang sangat tinggi namun tidak dapat diseimbangkan dengan adanya saluran pembuangan air yang memadai sehingga menyebabkan bertambahnya jumlah korban jiwa yang tinggi secara tak terduga. Pada topik pembahasan ini menjadi hal utama dalam mencari solusi pengurangan korban jiwa.

Ketinggian level debit air pada suatu tempat atau daerah dapat dipermudah dengan menggunakan alat modern seperti Water Level. Komponen ini digunakan sebagai alat pemberitahuan pada suatu tempat atau daerah untuk menampilkan level batas ketinggian air dengan status darurat. Sensor ini berfungsi dengan baik apabila adanya penggabungan dengan komponen lain seperti Buzzer. Buzzer biasa digunakan pada rangkaian anti-maling, 
bel rumah, peringatan mundur pada kendaraan roda empat dan peringatan bahaya lainnya. Secara otomatis apabila tegangan listrik yang diberikan ke komponen ini akan menyebabkan gerakan mekanis, gerakannya diubah menjadi suara atau bunyi yang dapat didengar oleh telinga manusia dengan menggunakan diafragma dan resonator. Buzzer dapat bekerja dengan baik untuk menghasilkan frekuensi dikisaran $1-5 \mathrm{kHz}$ hingga $100 \mathrm{kHz}$ untuk yang berbasis pada arduino. Tegangan operasional buzzer pada umumnya berkisar diantara 3 Volt hingga 12 Volt. Sehingga penggabungan komponen ini menjadi hal utama Water Level sensor sebagai alarm pemberitahuan.

Tujuan dari penelitian ini agar menghindari bertambahnya jumlah korban jiwa akibat bencana banjir dan agar masyarakat lebih cepat mengetahui akan datangnya banjir secara tiba-tiba. Dan dengan adanya arduino sebagai solusi dalam mengantisipasi akan datangnya banjir pada suatu tempat atau daerah maka perlu adanya tambahan komponen hardware seperti HC-SR04 Ultrasonic serta LCD 16x2(Liquid Crystal Display). HC-SR04 Ultrasonic yang berperan dalam mengatur jarak akan datangnya air sebelum mendekati batas status darurat pada suatu tempat. Gelombang HC-SRO4 Ultrasonic ini menyimpan frekuensi tinggi yaitu kisaran $20 \mathrm{kHz}$. Bunyi ini tidak bisa di dengar oleh telinga normal manusia. Sifat dari gelombang ini dapat merambat melalui zat cair dan padat. Maka untuk membaca jumlah jarak gelombang HC-SRO4 Ultrasonic perlu adanya penggabungan pada komponen lain seperti $L C D$ 16x2(Liquid Crystal Display) sebagai komponen yang menampilkan jumlah angka dalam mengatur jarak level debit air.

Solusi komponen tambahan ini menjadi alat pendukung dalam mengantisipasi akan datangnya kebanjiran sehingga masyarakat mampu menyelamatkan diri terdahulu ditempat evakuasi yang aman. Seluruh komponen akan bekerja dengan baik apabila disederhanakan dengan arduino. Guna kedepannya penelitian ini diharapkan dapat memberikan kontribusi bagi BMKG (Badan Meteorologi, Klimatologi dan Geofisika) khususnya dikota Pematangsiantar.

\section{TINJAUAN PUSTAKA}

\subsection{Musibah Banjir}

Banjir adalah suatu peristiwa tingginya aliran sungai dimana air menggenangi wilayah dataran banjir. Bencana banjir diukur dengan probabilitas terjadinya kerusakan yang secara umum disebut sebagai risiko banjir atau dampaknya terhadap masyarakat seperti korban jiwa atau kerusakan material masyarakat. Banjir merupakan salah satu bentuk fenomena alam yang terjadi akibat intensitas curah hujan yang tinggi di mana terjadi kelebihan air yang tidak tertampung oleh suatu sistem (Ecodrainage et al., 2019).

\subsection{Arduino Uno}

Arduino merupakan sistem mikroprosesor lengkap yang terkandung didalam sebuah chip yang memadukan CPU, ROM, RMW, I/O paralel,I/O seri,counter timer dan rangkaian clock didalamnya. Dengan kata lain arduino adalah sebuah alat elektronika yang mempunyai masukan dan keluaran serta kendali dengan program yang bisa ditulis dan dihapus dengan cara yang tertentu (Frianto et al., 2016).

Bentuk Arduino Uno dapat di lihat pada Gambar 1 di bawah ini:

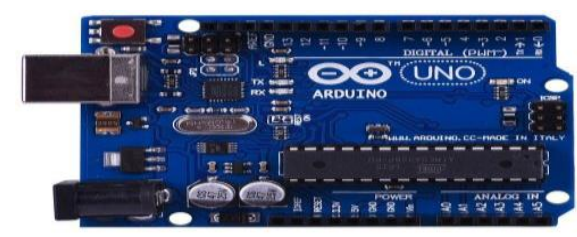

Gambar 1. Arduino Uno

\subsection{Water Level Sensor}

Water level sensor adalah komponen yang dirancang untuk mendeteksi ketinggian batas air. Terdiri dari tiga bagian yaitu electronic brick conneter, resistor $1 \mathrm{MQ}$ dan sejumlah jalur kabel konduktif telanjang. Sensor ini bekerja dengan memiliki serangkaian jejak terbuka yang terhubung ke ground dan interlaced. Antara ground bekas jejak. Jejak sensor memiliki resistor pull-up yang lemah sebesar $1 \mathrm{MQ}$. 
Resistor akan menarik nilai jejak sensor paling tinggi sampai setetes air terpendek yang dilacak sensor ke jejak ground.

Water Level Sensor dapat dilihat pada Gambar 2 berikut ini.

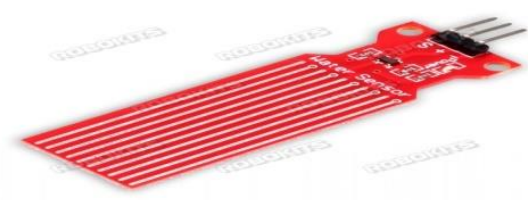

Gambar 2. Water Level Sensor

\subsection{Kabel Jumper}

Kabel jumper merupakan kabel dengan isi tunggal yang dipakai untuk menghubungkan antara titik satu dengan titik lainnya didalam satu projectboard (Panjaitan et al., 2021) dan kaber jumper juga berguna untuk menjadi penghubung antara komponen satu dengan komponen yang lainya. Berikut adalah kabel jumper dapat dilihart pada Gambar 3.

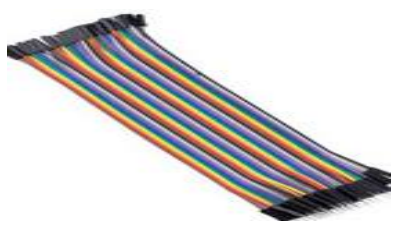

Gambar 3. Kabel Jumper

\subsection{Ultrasonic HC-SR04}

Ultrasonic HC-SRO4 merupakan sensor yang berfungssi untuk mengubah besaran fisis (bunyi) menjadi besaran listrik (Kresnha et al., 2018). Cara kerja sensor ini berprinsip dari pantulan suatu gelombang suara sehingga dapat digunakan untuk menafsirkan eksistensi/jarak suatu benda dengan frekuensi tertentu. Gelombang Ultrasonic HC-SRO4 memiliki frekuensi sangat tinggi yaitu $20.000 \mathrm{~Hz}$. Bunyi pada Ultrasonic HC-SRO4 tidak dapat didengar oleh telinga manusia.

Gambar Ultrasonic HC-SR04 dapat dilihat pada Gambar 4 berikut ini:

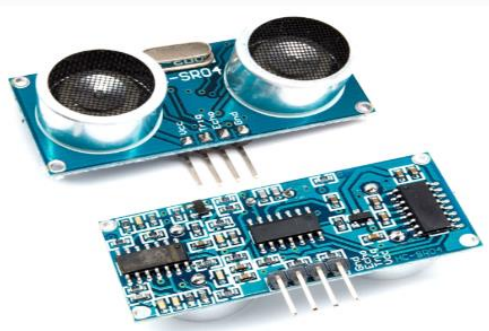

Gambar 4. NodeMCU

\subsection{Buzzer Alarm}

Buzzer adalah sebuah komponen elektronika yang mengubah energy listrik menjadi energy mekanik atau getaran. Energy getaran ini akan mengahasilkan suara. Buzzer juga biasanya digunakan untuk indicator suara untuk alarm, input keypad dan pemberitahuan darurat pada sebuah system electronic seperti di motherboard komputer (Ummul Khair, 2020).

Buzzer Alarm dapat dilihat pada Gambar 5 dibawah ini: 




Gambar 5. Buzzer Alarm

\subsection{LCD (Liquid Crystal Display)}

LCD merupakan sebuah alat yang berfungsi untuk menampilkan suatu ukuran besaran atau angka, sehingga dapat dilihat dan diketahui melalui tampilan layar krsitalnya. LCD memiliki 16 nomor pin. Pin juga memiliki tanda simbol dan juga fungsinya. LCD beroperasi pada power supply $+5 \mathrm{~V}$ akan tetapi juga mampu beroperasi pada power supply +3V (Mappa \& Jamlean, 2019).

$L C D$ dapat dilihat pada Gambar 6 dibawah ini:



Gambar 6. LCD

\section{METODE PENELITIAN}

Metode penelitian ini tertulis tentang bagaimana cara sistematis yang di gunakan oleh para peneliti dengan tujuan mendapatkan jawaban yang tepat atas apa yang menjadi pertanyaan pada objek penelitian atau upaya untuk mengetahui sesuatu dengan rangkaian sistematis.

Penelitian ini membahas tentang penggunaan sistem water level sebagai pendeteksi ketinggian dan alarm pemberitahuan dalam situasi status darurat. Adapaun penggunaan sistem water level meliputi perangkat keras (Hardware) dan perangkat lunak (Software).

\subsection{Rancangan Penelitian}

Pada system penggunaan sistem water level sebagai pendeteksi ketinggian dan alarm pemberitahuan dalam situasi status darurat ini, penulis membuat beberapa tahapan perancanangannya, mulai dari pengambilan data sampai dengan pengolahan yang akan dibuat sehingga hasil outputnya lebih jelas.

Gambar Rancangan penelitian dapat dilihat pada Gambar 7. Adapun penjelasan Rangkaian Penelitian yang di buat penulis seperti pada Gambar 7 adalah sebagai berikut:

1. Identifikasi Masalah

Pengenalan suatu masalah dan tahap awal dalam proses penelitian. Permasalahan penelitian ini adalah pendeteksi dan alarm pemberitahuan antisipasi akan datangnya banjir menggunakan water level sensor.

2. Pengumpulan Data

Data pada penelitian ini diperoleh dikelurahan banjar, kecamatan siantar barat, kota Pematangsiantar.

3. Pengolahan Data 
Pada langkah ini data-data yang sudah diperoleh dari studi identifikasi masalah dan pengumpulan data yang kemudian diolah untuk menyelesaikan permasalahan yang ditemukan.

4. Studi Literatur

Metode pengumpulan data yang menggunakan beberapa jurnal sebagai referensi untuk penulis.

5. Observasi

Metode pengumpulan data dengan mengamati wilayah vital rawan banjir seperti sungai-sungai kecil dengan akses padat penduduk.

6. Perancangan Komponen

Tahap ini adalah merancang sebuah komponen sistem water level untuk dapat menyelesaikan permasalahan yang dialami.

7. Pengujian Komponen

Melakukan pengujian sistem water level sebagai pendeteksi ketinggian air dan alarm pemberitahuan antisipasi akan datangnya banjir.

8. Hasil

Menghasilkan komponen yang dirancang dan mengimplementasikan komponen yang dibuat agar dapat digunakan sedemikian rupa.

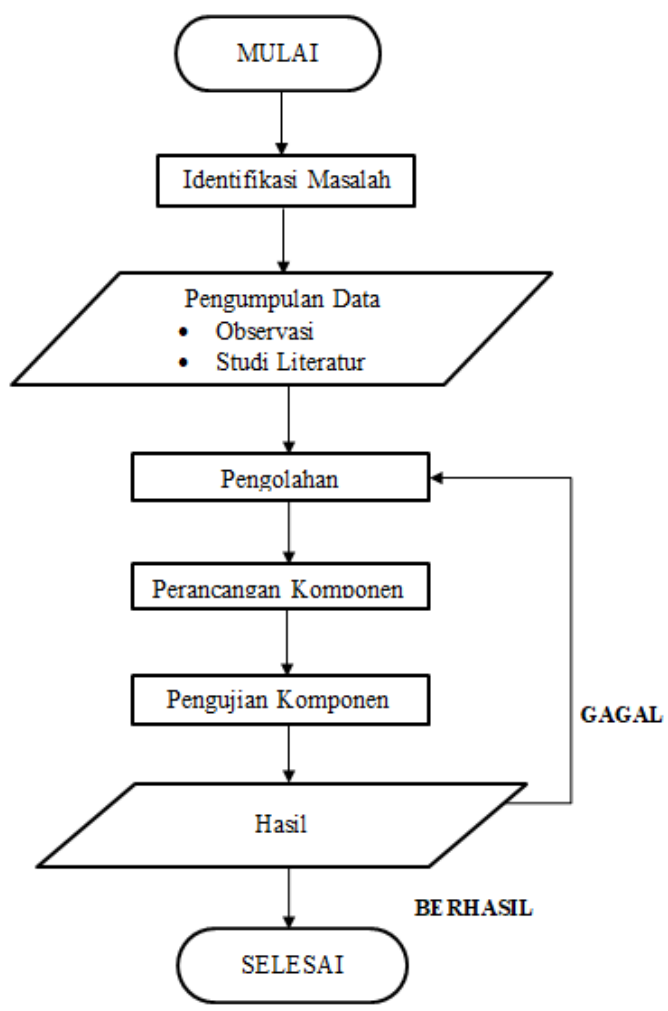

Gambar 7. Rangkaian Penelitian

\subsection{Perancangan Perangkat Keras}

Dalam meringankan perancangan sistem ini maka penulias akan memakai blok diagram untuk tahapan awal dalam proses pembuatannya, dimana blok diagram ini digunakan untuk menampilkan bagaimana cara kerja sistem ini dilakukan secara umum. Sistem rangkaian dapat dilihat pada Gambar 8 .

Pada Gambar 8 terdapat beberapa komponen perangkat keras system penggunaan sistem water level sebagai pendeteksi ketinggian dan alarm pemberitahuan dalam situasi status darurat ini, antara lain: 1. LCD (Liquid Crystal Display) berfungsi untuk menampilkan suatu ukuran besaran atau angka yang terlihat melalui tampilan layar kristalnya. 
2. Arduino Uno R3 berfungsi sebagai pusat kendali yang berupa ic mikrokontroler.

3. Ultrasonic HC-SR04 berfungsi dalam pantulan gelombangnya dapat menafsirkan eksistensi/jarak suatu benda dengan frekuensi tertentu.

4. Water level sensor berfungsi untuk mendeteksi ketinggian batas air.

5. Buzzer berfungsi sebagai indicator suara untuk alarm pemberitahuan.

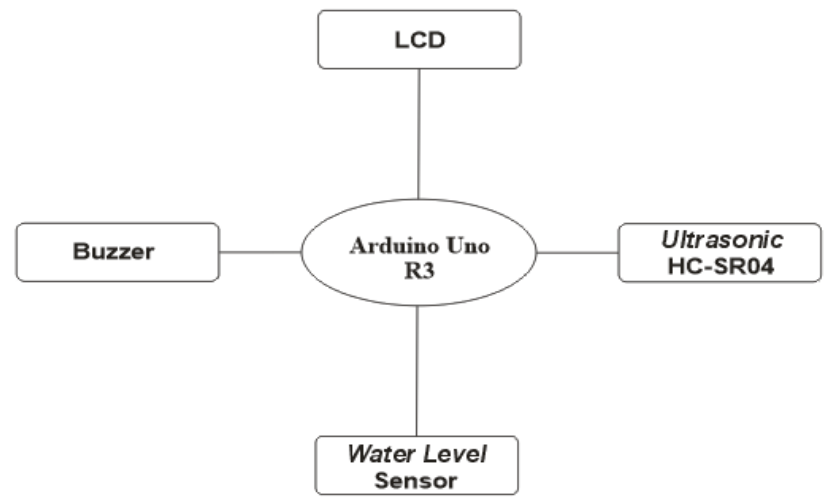

Gambar 8. Blok diagram

\subsection{Cara Kerja Alat}

Perancangan sistem menggunakan komponen water level sensor dan ultrasonic HC-SR04 yang diproses oleh perintah yang disimpan dalam chip mikrokontroler arduino. Adapun cara kerja alat yang dirancang ini adalah sebagai berikut.

1. Mulai

2. LCD memberi informasi

3. Membaca status level ketinggian air

4. Jika LCD memberi informasi ketinggian air mencapai $75 \%$ maka penduduk harus meninggalkan lokasi.

5. Jika Buzzer berbunyi maka wilayah dalam status darurat dan penduduk harus telah dievakuasi ditempat yang lebih aman.

6. Sistem selesai dijalankan.

\section{HASIL DAN PEMBAHASAN}

Komponen yang telah dirancang kemudian akan diteruskan ke tahap pengujian. Sebagaimana diketahui pada bab sebelumnya komponen dirakit berdasarkan dengan bentuk yang sudah digambarkan. Adapun rancangan untuk miniatur pada komponen ini adalah akuarium kaca dengan tinggi $30 \mathrm{~cm}$ dan lebar $15 \mathrm{~cm}$. Kemudian komponen Ultrasonic HC-SRO4 diletak tepat diatas kaca sebagai pengukur jarak objek bersamaan dengan komponen Water Level sensor untuk sistem kendali peringatan darurat lalu dikirim ke sensor untuk diproses pada arduino sehingga mendapatkankan hasil yang ditampilkan pada LCD.

Skema rangkaian keseluruhan alat ini dapat dilihat pada Gambar 9. Adapun dari skema rangkaian yang terlihat pada Gambar 9 kemudian dirangkai dengan instalasi dan pemasangan arduino dan modul lainnya dengan mengoneksikan atau menyambungkan pin di setiap modul ke pin yang terdapat pada arduino uno tersebut. Pin yang saling terkoneksi pada Gambar 9 dapat dijelaskan sebagai berikut.

1. Penyesuaian pin pada rangkaian arduino uno yang ada di code program yang dibuat.

2. Kaki SCL I2C LCD dikoneksikan pada pin A5 Arduino.

3. Kaki SDA I2C LCD dikoneksikan pada pin A4 Arduino.

4. Kaki VCC I2C LCD dikoneksikan pada pin 5V Arduino.

5. Kaki GND I2C LCD dikoneksikan pada pin GND Arduino.

6. Kaki VCC Sensor Ultrasonic dikoneksikan pada pin 5V Arduino.

7. Kaki Trig Sensor Ultrasonic dikoneksikan pada pin 4 Arduino. 
8. Kaki Echo Sensor Ultrasonic dikoneksikan pada pin 2 Arduino.

9. Kaki GND Sensor Ultrasonic dikoneksikan pada pin GND Arduino.

10. Kaki $(S)$ Sensor Water dikoneksikan pada pin A1 Arduino.

11. Kaki (+) Sensor Water dikoneksikan pada pin 5V Arduino.

12. Kaki (-) Sensor Water dikoneksikan pada pin GND Arduino.

13. Kaki (+) Buzzer Alarm dikoneksikan pada pin 5V Arduino.

14. Kaki (-) Buzzer Alarm dikoneksikan pada pin GND Arduino.

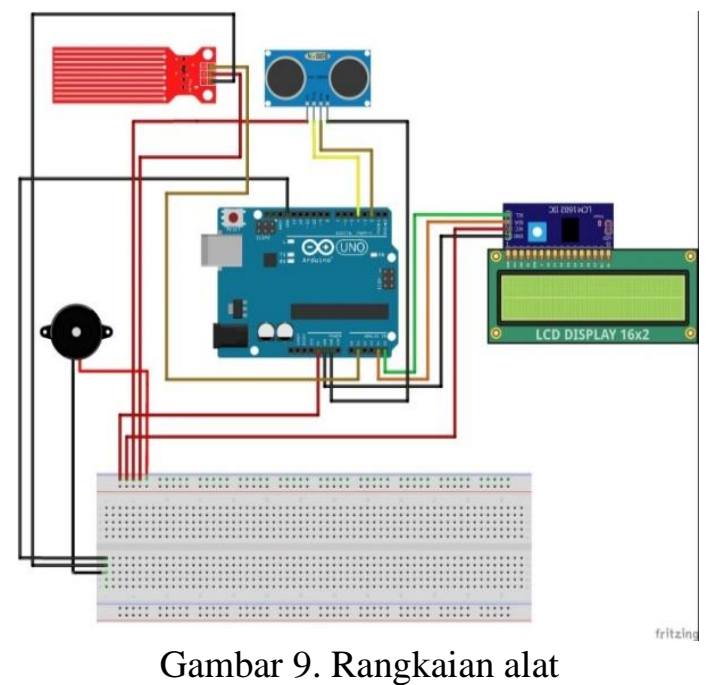

Adapun tambahan pada rangkaian ini yakni pin 5V dan pin GND dikoneksikan pada Bread Board untuk menambah jumlah yang tidak tersedia lagi. Setelah melakukan rangkaian koneksi pin modul ke dalam arduino proses berikutnya adalah melakukan perintah kepada arduino dengan berupa code program menggunakan bahasa C++ pada Software Arduino IDE. Sehingga rangkaian yang telah diterapkan dapat berjalan sesuai dengan yang penulis harapkan.

\subsection{Rangkaian Fisik Alat}

Rangkaian fisik system penggunaan sistem water level sebagai pendeteksi ketinggian dan alarm pemberitahuan dalam situasi status darurat ini. Dapat dilihat pada Gambar 10 di bawah ini.



Gambar 10. Rangkaian Fisik alat 


\subsection{Validasi Data}

Dalam pengujian komponen, penulis telah melakukan rancangan dengan 4 kategori dalam batasbatas tinggi air. Sehingga dapat diketahui ukuran dan jarak yang telah dirancang. Berikut ini adalah validasi data berdasarkan 4 kategori pada tabel berikut ini

Tabel 1. Hasil 4 Kategori Validasi Data

\begin{tabular}{rcccl}
\hline Kategori & Status & $\begin{array}{c}\text { Output } \\
\text { Led }\end{array}$ & $\begin{array}{c}\text { Jarak Antara } \\
(\mathbf{c m})\end{array}$ & \multicolumn{1}{c}{ Sistem Komponen } \\
\hline $25 \%$ & Siaga IV & Normal & $21 \mathrm{~cm} \mathrm{~s} / \mathrm{d} 30 \mathrm{~cm}$ & $\begin{array}{l}\text { LCD : Aktif } \\
\text { Ultrasonic: Aktif }\end{array}$ \\
$50 \%$ & Siaga III & Waspada & $16 \mathrm{~cm} \mathrm{~s} / \mathrm{d} 20 \mathrm{~cm}$ & $\begin{array}{l}\text { LCD: Aktif } \\
\text { Ultrasonic : Aktif }\end{array}$ \\
$75 \%$ & Siaga II & Evakuasi & $11 \mathrm{~cm} \mathrm{~s} / \mathrm{d} 15 \mathrm{~cm}$ & $\begin{array}{l}\text { LCD : Aktif } \\
\text { Ultrasonic : Aktif }\end{array}$ \\
& & & & $\begin{array}{l}\text { LCD : Aktif } \\
\text { Ultrasonic : Aktif } \\
100 \%\end{array}$ \\
& Siaga I & Darurat & $0 \mathrm{~cm} \mathrm{s/d} 10 \mathrm{~cm}$ & $\begin{array}{l}\text { Water Level : Aktif } \\
\text { Buzzer : Aktif }\end{array}$ \\
\hline
\end{tabular}

Pada tabel diatas dapat dilihat 4 tingkat pada pendeteksi ketinggian air dengan status maksimal $100 \%$ adalah siaga I dan output status darurat pada jarak tinggi air mulai dari $0 \mathrm{~cm} \mathrm{~s} / \mathrm{d} 10 \mathrm{~cm}$ terhitung secara mundur ke atas pada akurium kaca untuk menampilkan jarak tinggi air. Dengan demikian dapat dinyatakan sistem arduino water level sebagai pendeteksi ketinggian air dan alarm pemberitahuan antisipasi akan datangnya banjir dapat bekerja dengan baik.

\subsection{Pengujian Alat}

Setelah melakukan validasi data untuk pengujian dari komponen utama sistem, maka proses selanjutnya adalah penulis akan menjelaskan prosedur kerja sistem. Ini bertujuan untuk memastikan bahwa seluruh kinerja sistem bekerja dengan baik, stabil, akurat dan sesuai rancangan yang telah dibahas sebelumnya.

Tahapan awal pengujian keseluruhan sistem ini memberikan sumber arus listrik 5 Volt DC melalui adaptor 5 Volt DC. Kemudian modul arduino dan sensor akan mengkonfigurasi dirinya sendiri selama 30 detik sampai dengan 1 menit. Ini berguna untuk memeriksa semua sensor dan modul berfungsi dengan semestinya. Jika terjadi kesalahan pada semua modul ataupun sensor, LCD tidak akan menampilkan teks apapun pada layar. Jika semua sensor dapat berfungsi, maka sistem akan melaporkan status kondisi aktif berupa tampilan awal "SIAGA IV 25\% : NORMAL" pada LCD.

Setelah sistem aktif dan siap beroperasi, sistem akan bekerja dan sensor akan membaca bidang pantul yang ada dibawah sensor, maka sistem akan mengirim hasil proses pendeteksiannya yang akan ditampilkan pada LCD dengan format teks.

\subsection{Prosedur Sistem Kerja}

1. Masukan (input)

Perangkat lunak pada program arduino ini menggunakan software arduino IDE yang berbasis $\mathrm{C}++$ dengan sikronisasi melalui library. Arduino menggunakan Software Processing yang digunakan untuk menulis program ke dalam arduino.

Sebelum menggunakan komponen sistem kendali water sensor, terlebih dahulu harus dimasukan (input) berupa code-code agar arduino bekerja sesuai dengan ketentuan yang telah penulis harapkan. Untuk proses masukan (input) program ke dalam sebuah arduino, dibutuhkan driver USB, IDE Arduino versi 1.8.12., Arduino Board dan lain-lain agar program yang dibuat dapat berjalan di dalam arduino. 
2. Pemrosesan (Procces)

Data yang diterima dari sensor Ultrasonic HC-SR04 dan Sensor Water Level kemudian akan di proses oleh arduino dan hasil akan ditampilkan ke dalam LCD (Liquid Crystal Display) dan apabila telah mencapai angka 100\% maka Buzzer akan aktif dan berbunyi alarm.

3. Keluaran (Output)

Pada hasil keluaran (Output) pendeteksi ketinggian air dihitung secara 4 kategori dengan status maksimal di angka 100\% sebagai siaga 1 dalam status darurat. Maka dalam status darurat LCD memberikan hasil output bersamaan dengan Buzzer alarm pemberitahuan. Berikut ini adalah hasil output pada tampilan LCD Gambar 11.

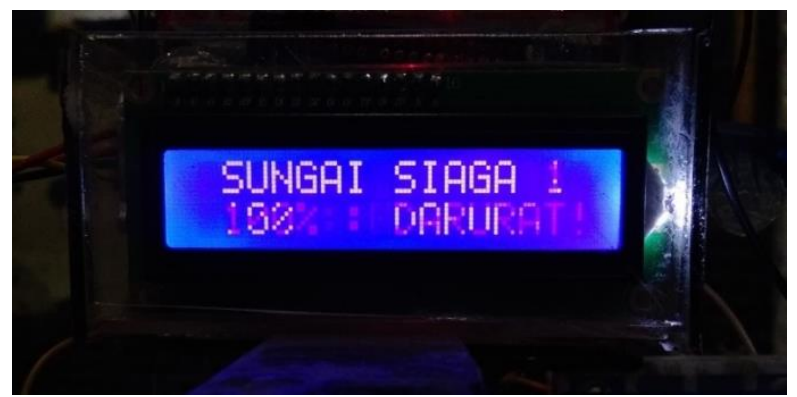

Gambar 11. Keluaran (Output)

\section{KESIMPULAN}

Kesimpulan yang didapat adalah dengan menggunakan Arduino Atmega328P yang dihubungkan dengan sensor Ultrasonic HC-SRO4 dan sensor Water Level yang digunakan untuk membangun sebuah interface antara sistem dengan subsistem lainnya yang membentuk suatu integrasi sistem dalam membentuk satu kesatuan. Pada komponen pendeteksi ketinggian air dan alarm pemberitahuan ini setelah dilakukannya uji komponen maka dapat disimpulkan bahwa komponen ini berhasil dijalankan sesuai dengan kondisi yang terdeteksi oleh sensor Water Level sebagai status siaga I dikategori 100\% yaitu darurat serta sensor Ultrasonic HC-SRO4 sebagai pengatur jarak tinggi air dengan memberikan tampilannya pada layar LCD (Liquid Crystal Display).

\section{DAFTAR PUSTAKA}

Ecodrainage, M., Ekosistem, P., Tungu, D., Girimulyo, D., Panggang, K., Gunungkidul, K., Santoso, D. H., Artikel, S., \& Kunci, K. (2019). Penanggulangan Bencana Banjir Berdasarkan Tingkat Kerentanan dengan Metode Ecodrainage Pada Ekosistem Karst di Dukuh Tungu, Desa Girimulyo, Kecamatan Panggang, Kabupaten Gunungkidul, DIY. Jurnal Geografi, 16(1), 7-15. https://doi.org/10.15294/jg.v16i1.17136

Frianto, H. T., Anwar, Salman, A., Hasman, J., Lubis, R., Nasruddin, Murtopo, \& Gunawan. (2016). Absensi Mahasiswa Menggunakan Sensor Rfid Untuk Perhitungan Kompensasi Kehadiran. Jurnal Riset Komputer (JURIKOM), 3(1), 113-116.

Kresnha, P. E., Atmaja, D. T., Darda, F. F. I., \& Alfian, R. (2018). Perancangan Alat Sensor Parkir Perintah Suara Menggunakan MP3 Shield Arduino. Jurnal Sistem Informasi, Teknologi Informatika Dan Komputer, 9(September), 49-54.

Mappa, A., \& Jamlean, A. (2019). Rancang Bangun Sistem Kendali Dan Monitoring Level, Debit Air Dan Proteksi Pompa Listrik. Electro Luceat, 5(1), 5-15. https://doi.org/10.32531/jelekn.v5i1.126

Panjaitan, F., Nasution, Z. M., \& Gunawan, I. (2021). Penggunaan Radio Frequency Identification dalam Proses Absensi Kehadiran Pegawai Menggunakan Arduino. 1(2), 131-138.

Ummul Khair. (2020). Alat Pendeteksi Ketinggian Air Dan Keran Otomatis Menggunakan Water Level Sensor Berbasis Arduino Uno. Wahana Inovasi : Jurnal Penelitian Dan Pengabdian Masyarakat UISU, 9(1), 9-15. https://jurnal.uisu.ac.id/index.php/wahana/article/view/2632 


\section{Halaman Ini Dikosongkan}

